\title{
INCIDENCE OF SUTURAL BONES WITH SPECIAL REFERENCE TO SEX - A STUDY IN THE EASTERN REGION OF INDIA
}

Anirban Sadhu¹, Rudradev Meyur², Banani Kundu³, Abhijit Bhakta4, Biplab Goswami ${ }^{5}$, Subhasis

Chakraborty6, Sharmistha Biswas ${ }^{7}$, Phalguni Srimani ${ }^{8}$

\begin{abstract}
HOW TO CITE THIS ARTICLE:
Anirban Sadhu, Rudradev Meyur, Banani Kundu, Abhijit Bhakta, Biplab Goswami, Subhasis Chakraborty, Sharmistha Biswas, Phalguni Srimani. "Incidence of sutural bones with special reference to s ex - a study in the eastern region of India”. Journal of Evolution of Medical and Dental Sci ences 2013; Vol. 2, Issue 45, November 11; Page: 8729 8735.
\end{abstract}

ABSTRACT: Context (Background): Many authors have studied sutural bones in various parts of the world. Examples of such work done in the Eastern Region of India are not known to many in the medical community. Therefore, the authors have endeavored to give some insight into the topic and compile a baseline data of such traits by studying the incidence and distribution of various types of sutural bones in the Eastern region of India. AIMS: To study the incidence and distribution of various types of sutural bones in the Eastern region of India with particular attention to sex distribution. SETTINGS AND DESIGN: A cross-sectional observational study was conducted based on dry adult crania in the museum of Department of Anatomy over a period of 1 year. METHODS AND MATERIAL: 111 dry adult crania were selected as per inclusion and exclusion criteria. The number of crania with sutural bones in each sex, the total number of sutural bones in each sex and the distribution of sutural bones present bilaterally and in the midline in both males and females were studied. STATISTICAL ANALYSIS: Z-Test was performed for the distribution of sutural bones. A p-value $<0.05$ was considered significant. The results were calculated using Epi Info ${ }^{\mathrm{TM}}$ statistical software (version 3.4.1 July 3, 2007 for Windows). RESULTS: The gross incidence of sutural bones was $69.37 \%$. The gross percentages of males and females with sutural bones were 38.74 and 30.63 respectively. Higher number of sutural bones were observed in females (188) compared to males (153). There was a statistically significant difference in the distribution of LO type of sutural bone present bilaterally between male and female crania. CONCLUSION: Minor variations in the ossicles of the cranium have aroused the curiosity of anatomists for many decades. Studies have shown that the presence of sutural bones is associated with other cranial and central nervous system abnormalities. The presence of sutural bones as small island s of bone lying within the lambda should not be confused with fractures of the skull. Thus these are important for radiologists, surgeons and forensic personnel. Further investigation into the cause of differences in the distribution of sutural bones may lead to the unraveling of developmental events associated with them.

INTRODUCTION: Minor variations in the ossicles of the cranium have aroused the curiosity of anatomists for many decades ${ }^{1}$. Sutural bones are commonly observed in or near sutures of the skull bones $^{2}$. These bones have great antiquity, having been observed by Dart (1948) in the Australopithecine cranial fragments from Makapansgat ${ }^{3}$. Various authors have put forward their views on this subject after studying such bones in their respective regions. However, very few of them represent the Eastern region of India.

It has been noted that sutural bones are usual in many mammals ${ }^{4}$. The association of sutural bones with skull size, development and climatic tolerances of different people have also been 
suggested ${ }^{5}$. Sutural structures have been shown to be genetically determined but environmental factors are responsible for their adult morphology (Oudhof, 1982) ${ }^{6}$.

Sutural bones may represent a pre-interparietal element, a true inter-parietal element or some composite 2 . One or more pterion ossicles or epipteric bones may appear between the sphenoidal angle of the parietal and the greater wing of the sphenoid $2,7,8$. Ossicles as sutural bones have been also observed in coronal, lambdoid and sagittal sutures as well as at asterion, between squamous and mastoid portion of the temporal bone and in the occipito-mastoid suture?

Sutural bones are usually normal variants which can be detected prenatally. However some syndromes are associated with it. These are easily remembered by the PORKCHOPS mnemonic ${ }^{9}$ : PPyknodysostosis, 0-Osteogenesis Imperfecta, R-Rickets, K-Kinky Hair Syndrome, C-Cleidocranial Dysostosis, H-Hypothyroidism / Hypophosphatasia, O-Otopalatodigital Syndrome, P-Primary Acroosteolysis, S-Syndrome of Downs. It was Wood Jones (1930-1) ${ }^{10}$, however, who first proposed that the differing incidences of these minor variants which occurred in different races might be useful in anthropological studies. Laughlin and Jorgensen (1956) ${ }^{11}$ put this idea into practice and Berry and Berry (1967) ${ }^{7}$ suggested that a wide range of these variants could be used to calculate a distance statistic between population samples.

\section{METHODS AND MATERIALS:}

Study design: A cross-sectional observational study was undertaken.

Study type: It is an epidemiological observational type of study.

Scope and delimitation: The research is limited to:

(1) dry adult human crania with no observable craniofacial abnormalities and no teeth,

(2) observations recorded by single person and

(3) crania with all study parameters present prominently.

Study area: The study was conducted at the Department of Anatomy of R G Kar Medical College, Kolkata which is a very old and renowned institute. It receives human skeletal parts from majority of Eastern India.

Study population: One hundred and eleven dry adult human crania were selected from the musea of the study area, according to the following criteria:

(1) crania of macerated dead humans received by the institutions mentioned before,

(2) crania belonging to the late 19th century till death as per records,

(3) crania with no observable craniofacial deformities and

(4) crania with a unique alpha numeric code

These crania were divided into two groups as detailed in Table I

Crania were chosen randomly, placed on the cushion in Frankfurt Horizontal and the following noted:

(1) identification number - an alpha numeric code which was made with black paint, eg, XY 20 where XY refers to the institution of origin and 20 the particular number of that cranium.

(2) total number of crania with sutural bones each in male and female

(3) total number of sutural bones each in male and female crania

(4) distribution of different types of sutural bones present bilaterally between male and female crania 
(5) distribution of different types of sutural bones present in the midline between male and female crania

The different types of sutural bones studied are depicted in Table II. The sutural bones were subdivided into two groups: 1 . Bones present bilaterally - CO, LO, OA, OMB, PNB and PO 2. Bones present in the midline - BO/ OB, OL and SO. Bones in these two groups were studied in both male and female.

Statistical analysis: The results were calculated using Epi Info ${ }^{\mathrm{TM}}$ statistical software (version 3.4.1 July 3, 2007 for Windows) and a significance level of $\mathrm{p}<0.05$ was considered significant.

RESULTS: 43 male and 34 female crania were found to have sutural bones with an incidence of $38.74 \%$ and $30.63 \%$ respectively (Table I). The gross incidence of sutural bones was $69.37 \%$. No $\mathrm{OB} / \mathrm{BO}$ and $\mathrm{OMB}$ were found in the present study. There was a statistically significant difference in the distribution of LO type of sutural bone present bilaterally between male and female crania (Table III).There was no statistically significant difference in the distribution of different types of sutural bones present in the midline between male and female crania (Table IV). LO and CO were the sutural bones with the highest (39.49\%) and lowest (0.82\%) incidence respectively (Table V).

DISCUSSION: Sutural bones are most common at the borders of the parietal bone ${ }^{12}$. The prevalence of sutural bones in the general population varies from $8-15 \%$ and males are more affected than females ${ }^{13}$.The gross incidence of sutural bones was $69.37 \%$ in the present study which is much more than $45 \%$ reported by Trivedi et al (2011) ${ }^{14}$. However it falls well within the range of 55.56 to 80.32 $\%$ reported by Brothwell (1963) ${ }^{13}$. Higher number of sutural bones were observed in females (188) compared to males (153). The mean number of sutural bones was 3.56 and 5.53 in males and females respectively. Higher number of sutural bones were recorded on the right (74 in males and 93 in females) than on the left (64 in males and 80 in females). The gross percentages of males and females with sutural bones were 38.74 and 30.63 respectively since a higher number of males (43) with sutural bones were observed than females (34). The higher number observed in females may be due to the hypostotic nature of these traits which represent arrested morphogenesis and are characterized by a slight preference for females and for the right side. The faster growth rate in males either inhibits their formation or speeds up their obliteration (or both) while the slower rate in females produces stress which either encourages their formation or delays their closure (or both) ${ }^{15}$.Walulkar et al ${ }^{16}$ reported an incidence of $14.90 \%$ and $12.50 \%$ for males and females respectively with sutural bones. This sharp contrast with the present study further strengthens the view that these are epigenetic variants and vary from one population to another.

The percentage incidence of various sutural bones do not vary much from that of Gopinathan et al17. Trivedi et al (2011) found an incidence of $41.18 \%$ and $48.10 \%$ in females and males respectively. This might be due to the interplay of similar genetic processes during development in both these populations. However data regarding metric cranial variants are required to further corroborate this view. The mean measure of divergence between these populations can be used to compare relative proximities of the various races. Hence we can have an idea regarding the roots of origin, migration and final settlement of the various human races we observe today.

Berry and Berry (1967) ${ }^{18}$ in their study of epigenetic variations of 585 adult crania in humans found lambdoid ossicles (LO) to be most frequent across eight populations. Brunner et al 19 
found OA to be significantly correlated with Cranial Module (the latter is used as an index of cranial size). However, no such significance was encountered in the present study. Torgersen ${ }^{20}$ and Kjellgren ${ }^{21}$ opined that the most consistent factor influencing side differences is the slight retardation of ossification on the right side owing to richer innervation on that side, associated with cerebral hemisphere dominance and mediated, at least in part by the blood supply. The present study indicates a minor role of such innervation and blood supply in the distribution of such bones, instead it appears to be random in nature.

ACKNOWLEDGMENTS: The authors would like to express their sincere gratitude to all faculty members and non teaching staff of our institute for their whole-hearted support for this project.

\section{REFERENCES:}

1. Le Double AF. Variations des OS du Crane. Paris: Vigot 1903;400.

2. Standring $\mathrm{S}$ et al. HEAD Skull and Mandible In: Gray's Anatomy The Anatomical Basis of Clinical Practice Standring S (editor in chief), ELSEVIER Churchill Livingstone Philadelphia USA, 39/e, Chapter 27, 2005;486.

3. Dart RA. The Makapansgat proto-human Australopithecus prometheus. Am J Phys Anthrop 1948;6:259-84.

4. Joseph J. LOCOMOTOR SYSTEM In: Textbook of HUMAN ANATOMY Late Hamilton WJ (editor), The Macmillan Press Ltd London, 2/e, 1976;71.

5. Bennett KA. The Etiology and Genetics of Wormian Bones. Am J Phys Anthrop 1965;23:25560.

6. Oudhof HAJ. Sutural growth. Acta Anat 1982;112:58-68.

7. Berry AC, Berry RJ. Epigenetic variation in the human cranium. J Anat 1967;101(2):361-79.

8. Ahuja UK, Mukherjee RN, Singh B. PTERION-ITS FORMATION AND VARIATIONS. J Anat Soc India 1971;20(2):103-11.

9. Danhert, Wolfgang. Radiology Review Manual. Williams and Wilkins 1999.

10. Wood Jones F. The non-metrical morphological characters of the skull as criteria for racial diagnosis. I, II and III. J Anat 1930-31;65:179-95, 368-78, 438-45.

11. Laughlin WS, Jorgensen JB. Isolate variation in Greenlandic Eskimo Crania. Acta Genetica Statistica Medica (Basel) 1956;6:3-12.

12. Briggs CA, Martakis M. Craniofacial Anatomy In: Craniofacial Identification In Forensic Medicine Clement JG, Ranson DL (editors) Arnold Publishers London 1/e Chapter 4 1998;3747.

13. Brothwell DR. Digging Up Bones. British Museum of Natural History, London 1963.

14. Trivedi GN, Gour KK, Budhiraja V, Rastogi R, Nair S. Incidence of sutural bones in human skulls. Int J Curr Biol and Med Sc 2011;1(4):164-65.

15. Ossenberg NS. The influence of artificial cranial deformation on discontinuous, morphological traits. Am J Phys Anthrop 1970;33:357-71.

16. Walulkar SM, Shende MR, Ksheersagar DD, Pathak NK. Study of Wormian Bones in Human Skulls in Nagpur Region (Abstr). J Anat Soc India 2006;55(1):92.

17. Gopinathan K, Dhall U, Chhabra S. Sutural bones in the North Indian Population. J Anat Soc India 1998;47(2):91-6. 
18. Berry AC, Berry RJ. Epigenetic variation in the human cranium. J Anat 1967;101(2):361-79.

19. Brunner E, Averini M, Manzi G. Endocranial traits. Prevalence and distribution in a recent human population. Eur J Anat 2003;7(1):23-33.

20. Togersen J. Asymmetry and skeletal Maturation. Acta Radiologica 1951a;36:521-3.

21. Kjellgren K. Studien uber die Entwicklungen der Neuronen nach der Geburt, ihre Regeneration und die Asymmetrien ihrer Verteilung beim Menschen. Acta Psychologica et Neurologica 1944; Supplement 29.

\begin{tabular}{|l|l|l|}
\hline & Male (\%) & Female (\%) \\
\hline Crania with sutural bones & $43(38.74)$ & $34(30.63)$ \\
\hline Crania without sutural bones & $17(15.32)$ & $17(15.32)$ \\
\hline \multicolumn{2}{|c|}{ Table I: Distribution of crania with and } \\
without sutural bones in males and females
\end{tabular}

\begin{tabular}{|c|c|}
\hline Sutural bone & Description \\
\hline $\begin{array}{l}\text { Bregmatic Ossicle (BO)/ Ossicle at Bregma } \\
\text { (OB) }\end{array}$ & $\begin{array}{l}\text { A bone present at the junction of the Sagittal suture } \\
\text { with the Coronal one }\end{array}$ \\
\hline Coronal Ossicle (CO) & $\begin{array}{l}\text { A bone present in the Coronal suture. This was } \\
\text { scored as COr and COl for right and left sides } \\
\text { respectively }\end{array}$ \\
\hline Lambdoid ossicle (LO) & $\begin{array}{l}\text { One or more bones present in the Lambdoid suture. } \\
\text { This was scored as LOr and LOl for right and left } \\
\text { sides respectively }\end{array}$ \\
\hline Ossicle at Asterion (OA) & $\begin{array}{l}\text { A bone present at the Asterion which was scored as } \\
\text { Oar and OAl for right and left sides respectively }\end{array}$ \\
\hline Ossicle at Lambda (OL) & $\begin{array}{l}\text { A bone at the junction of the Sagittal and Lambdoid } \\
\text { sutures. No attempt was made to distinguish } \\
\text { between a sutural bone in this position, and a 'true' } \\
\text { interparietal or Inca bone formed from the } \\
\text { membranous part of the occiput. According to Wood } \\
\text { Jones this latter is very rare }{ }^{10,2}\end{array}$ \\
\hline Occipito Mastoid Bone (OMB) & $\begin{array}{l}\text { A sutural bone in the suture between Occiput and } \\
\text { Mastoid bone }\end{array}$ \\
\hline Parietal Notch Bone (PNB) & $\begin{array}{l}\text { Parietal notch is that part of the parietal bone that } \\
\text { protrudes between the squamous and the mastoid } \\
\text { portions of the temporal bone. It may form a } \\
\text { separate ossicle which is known as the parietal } \\
\text { notch bone. This was also scored as P NBr and PNBl } \\
\text { for right and left sides respectively }\end{array}$ \\
\hline Pterion ossicle (PO) & $\begin{array}{l}\text { A sutural bone (epipteric bone) inserted between } \\
\text { the anterior inferior angle of the parietal bone and } \\
\text { the greater wing of the sphenoid. When large it may }\end{array}$ \\
\hline
\end{tabular}




\begin{tabular}{|l|l|}
\hline & $\begin{array}{l}\text { also articulate with the squamous part of the } \\
\text { temporal bone. This was scored as POr and POl for } \\
\text { right and left sides respectively }\end{array}$ \\
\hline Sagittal Ossicle (SO) & A bone present in the Sagittal suture \\
\hline & Table II: Description of sutural bones studied \\
\hline
\end{tabular}

\begin{tabular}{|c|c|c|c|c|c|}
\hline & \multicolumn{5}{|c|}{ Type of sutural bone } \\
\hline & $\begin{array}{c}\text { LO } \\
\%(n)\end{array}$ & $\begin{array}{c}\text { PO } \\
\%(n)\end{array}$ & $\begin{array}{c}\text { PNB } \\
\%(n)\end{array}$ & $\begin{array}{c}\text { OA } \\
\%(n)\end{array}$ & $\begin{array}{c}\text { CO } \\
\%(n)\end{array}$ \\
\hline Male $(n=43)$ & $25.58(11)$ & $09.30(4)$ & $16.28(7)$ & $06.98(3)$ & $02.33(1)$ \\
\hline Female $(n=34)$ & $52.94(18)$ & $20.59(7)$ & $17.65(6)$ & $02.94(1)$ & $00.00(0)$ \\
\hline Z-statistic & 2.4600 & -1.4060 & -0.1590 & 0.7930 & - \\
\hline P-value & 0.0139* & 0.1597 & 0.8737 & 0.4278 & - \\
\hline
\end{tabular}

\begin{tabular}{|c|c|c|}
\hline \multirow{2}{*}{} & \multicolumn{2}{|c|}{ Type of sutural bone } \\
\cline { 2 - 3 } & $\begin{array}{c}\text { OL } \\
\mathbf{\%}(\mathbf{n})\end{array}$ & $\begin{array}{c}\text { S0 } \\
\mathbf{\%}(\mathbf{n})\end{array}$ \\
\hline Male (n=43) & $20.93(9)$ & $11.63(5)$ \\
\hline Female (n=34) & $29.41(10)$ & $08.82(3)$ \\
\hline Z-statistic & -0.8570 & 0.4010 \\
\hline P-value & 0.3914 & 0.6884 \\
\hline
\end{tabular}

Table IV: Comparison of the distribution of different types of sutural bones present in the midline between male and female crania

\begin{tabular}{|l|c|c|c|c|c|c|c|c|c|c|}
\hline \multicolumn{1}{|c|}{ Population } & $\begin{array}{c}\text { Sample } \\
\text { size }\end{array}$ & OB & SO & OL & CO & LO & PO & OA & PNB & OMB \\
\hline Eastern India & 111 & 0 & 2.25 & 3.89 & 0.82 & 39.49 & 8.8 & 4.3 & 9.82 & 0 \\
\hline North India & 89 & 0 & 1.12 & 12.40 & 3.37 & 30.30 & 6.74 & 12.4 & 11.24 & 5.62 \\
\hline Gujarati & 284 & 0 & 1.05 & 20.07 & 0 & 37.40 & 7.74 & 13.95 & 11.26 & 6.68 \\
\hline Punjabi & 53 & 0 & 0 & 20.07 & 1.9 & 32.1 & 16.9 & 9.8 & 7.5 & 0 \\
\hline Egyptian & 250 & 0.80 & 0 & 14.8 & 2.6 & 32.3 & 14.4 & 12.9 & 7.4 & 0 \\
\hline Palestine (modern) & 18 & 0 & 0 & 22.2 & 0 & 33.3 & 6.4 & 8.3 & 11.1 & 0 \\
\hline South American (Peru) & 53 & 0 & 0 & 15.9 & 1.9 & 45.2 & 7.5 & 14.2 & 11.3 & 0 \\
\hline Australian (Aborigines) & 1184 & 0.3 & 0 & 12.9 & 5.4 & 47 & 19.8 & 17.9 & 15.4 & 0 \\
\hline Caucasian & 139 & 0 & 2.87 & 10.7 & 1.43 & 37 & 12.94 & 10.76 & 11.05 & 0 \\
\hline Black (Negro American) & 182 & 0 & 1.09 & 12.63 & 0.27 & 22.5 & 2.19 & 7.96 & 7.14 & 0 \\
\hline
\end{tabular}




\section{AUTHORS:}

1. Anirban Sadhu

2. Rudradev Meyur

3. Banani Kundu

4. Abhijit Bhakta

5. Biplab Goswami

6. Subhasis Chakraborty

7. Sharmistha Biswas

8. Phal guni Srimani

\section{PARTICULARS OF CONTRIBUTORS:}

1. Assistant Professor, Department of Anatomy, R G Kar Medical College, 1, Kshudiram Bose Sarani, Kolkata, West Bengal, India.

2. Associate Professor, Department of Anatomy, R G Kar Medical College, 1, Kshudiram Bose Sarani, Kolkata, West Bengal, India.

3. Assistant Professor, Department of Anatomy, R G Kar Medical College, 1, Kshudiram Bose Sarani, Kolkata, West B engal, India.

4. Associate Professor, Department of Anatomy, NRS Medical College, 138, AJC Bose Road, Kolkata, West B engal, India.
5. Junior Resident, Department of Anatomy, R G Kar Medical College, 1, Kshudiram Bose Sarani, Kolkata, West Bengal, India.

6. Junior Resident, Department of Anatomy, R G Kar Medical College, 1, Kshudiram Bose Sarani, Kolkata, West Bengal, India.

7. Associate Professor, Department of Anatomy, NRS Medical College, 138, AJC Bose Road, Kolkata, West Bengal, India.

8. Junior Resident, Department of Anatomy, R G Kar Medical College, 1, Kshudiram Bose Sarani, Kolkata, West B engal, India.

\section{NAME ADDRESS EMAIL ID OF THE}

\section{CORRESPONDING AUTHOR:}

Dr. Anirban Sadhu, 2, Mahakalitala Lane, PO: Bansberia, Dist: Hooghly, PIN: 712502, West Bengal, India.

Email - anir_sd@ rediffmail.com

Date of Submission: 25/10/2013.

Date of Peer Review: 26/10/2013.

Date of Acceptance: 29/10/2013.

Date of Publishing: 05/11/2013 